ISSN: 1641-4713; e-ISSN: 2081-1160

DOI: https://doi.org/10.36551/2081-1160.2020.25.3-24

\title{
Hallar senderos pluriversales ${ }^{1}$
}

\section{Finding Pluriversal Paths}

\author{
Ashish Kothari \\ Atmiya Institute of Technology \& Science, Rajkot, Gujarat, India \\ E-mail: amkothari@aits.edu.in \\ Ariel Salleh \\ University of Sydney, Australia \\ E-mail: ariel.salleh@sydney.edu.au \\ Arturo Escobar \\ University of North Carolina at Chapel Hill, Estados Unidos \\ Universidad del Valle / Pontificia Universidad Javeriana, Colombia \\ E-mail: aescobar@email.unc.edu \\ Federico Demaria \\ Universidad Autónoma de Barcelona, España \\ E-mail: federicodemaria@gmail.com \\ Alberto Acosta \\ FLACSO-Ecuador, Ecuador \\ E-mail: alacosta48@yahoo.com
}

La crisis mundial actual es sistémica, múltiple y asimétrica; comenzó a gestarse hace mucho tiempo y hoy día afecta a todos los continentes. Nunca antes habían fallado simultáneamente tantos aspectos esenciales de la vida, ni las expectativas de la gente sobre el futuro de sus hijos habían sido tan inciertas. No podemos seguir ignorando los problemas ecológicos del planeta. Como un virus mutante, las manifestaciones de la crisis se perciben en todo tipo de ámbitos: ambiental, económico, social, político, ético, cultural, espiritual y personal. De igual modo, no podemos seguir barriendo debajo de la alfombra las abismales desigualdades que van en aumento a medida que el «desarrollo» abarca todas

\footnotetext{
${ }^{1}$ El texto fue publicado por primera vez en: Kothari, A., Salleh, A., Escobar, A., Demaria, F., y Acosta, A. (eds.). (2019). Pluriverso. Un diccionario del posdesarrollo (pp. 35-57). Barcelona, España: Icaria.
} 
las regiones del planeta. Dada la ausencia de narrativas convincentes, estamos atravesando una crisis ideológica; una crisis sobre el sentido de la historia. Aquí nos referimos a la palabra «crisis» no solo en relación a su significado habitual de «una época de dificultad intensa o de peligro», sino también a sus orígenes etimológicos en medicina, específicamente «al punto de inflexión de una enfermedad en el que acontece un cambio importante, dando lugar a la recuperación o la muerte» ${ }^{2}$. Por lo tanto, deberíamos centrar nuestros esfuerzos en convertir esta época de crisis en una época de oportunidad. Este libro es un gesto de renovación y de repolitización, en el que «lo político» es una lucha a favor de las clases de mundos que pretendemos crear.

La seductora naturaleza de la retórica del desarrollo, a veces llamada desarrollismo (Deb, 2009; Mies, 1986; Nandy, 2003: 164-175; Shrivastava y Kothari, 2012), ha acabado siendo internalizada en prácticamente todos los países. Aun muchas personas que padecen las consecuencias del crecimiento industrial en el Norte global aceptan una interpretación unilineal del progreso. Muchas naciones del Sur se han opuesto a propuestas de regulación ambiental global sugiriendo que el Norte intenta evitar que el Sur alcance su propio nivel de desarrollo. El debate internacional se desplaza entonces a las «transferencias monetarias y tecnológicas» del Norte hacia el Sur que, en beneficio del primero, no cuestiona las premisas básicas del paradigma del desarrollo. Estos términos, Norte y Sur globales, ya no se limitan a ser denominaciones geográficas, sino que son además económicas y geopolíticas (Salleh, 2006). Por lo tanto, la expresión Norte global puede referirse tanto a las naciones históricamente dominantes como a las élites dirigentes del Sur, colonizadas pero opulentas. De forma similar, para las nuevas alianzas alterglobalizadoras, el Sur global puede ser una metáfora que engloba tanto a las minorías étnicas y las mujeres explotadas en los países ricos como a los países históricamente colonizados o «pobres».

Décadas después de que la noción de desarrollo se expandiese por todo el mundo, solo un puñado de los países llamados subdesarrollados, en vías de desarrollo o Tercer Mundo - para usar términos despectivos de la Guerra Fría- han alcanzado la calificación de desarrollados. Otros luchan por emular el modelo económico del Norte, con enormes costes económicos y sociales. El problema no está en la falta de implementación de las medidas sugeridas, sino en concebir al desarrollo como crecimiento lineal, unidireccional, material y financiero, impulsado por la mercantilización y los mercados capitalistas.

\footnotetext{
${ }^{2}$ El término proviene del griego «krisis» (=decisión, u oportunidad).
} 
A pesar de los numerosos intentos de resignificar al desarrollo, continúa siendo algo que los «expertos» gestionan en pos del crecimiento económico, y miden según el PIB (Producto Interior Bruto), un deficiente y engañoso indicador del progreso en el sentido de bienestar. En realidad, el mundo en su conjunto padece de «maldesarrollo», incluso los países muy industrializados cuyo estilo de vida supuestamente serviría de modelo a las naciones «atrasadas».

Un aspecto crítico de estas crisis múltiples reside en la noción misma de «modernidad», sin que esto sugiera que todo lo moderno es destructivo o injusto o que todo lo tradicional es positivo. Sin duda, factores modernos como los derechos humanos y los principios feministas han demostrado ser liberadores para mucha gente. Nos referimos aquí a la modernidad como aquella cosmovisión dominante surgida en Europa a partir de la transición renacentista entre la Edad Media y el período moderno temprano y que alcanzó su consolidación a fines del siglo XVIII. Además, entre estas instituciones y prácticas culturales se potenció la creencia en «el individuo» independiente del colectivo y en la propiedad privada, los mercados libres, el liberalismo político, el secularismo ${ }^{3}$ y la democracia representativa. Otro rasgo esencial de la modernidad es la «universalidad», la idea de que todos vivimos en un único mundo, hoy globalizado, y fundamentalmente la noción de ciencia como única verdad fiable y precursora del «progreso».

Entre las causas tempranas de estas crisis encontramos la antigua premisa monoteísta de que un «Dios» padre creó la Tierra en beneficio de «sus» hijos humanos. Esta concepción se conoce como antropocentrismo ${ }^{4}$. Al menos en Occidente, esto derivó en el hábito filosófico de enfrentar a la humanidad con la naturaleza, dando origen así a dualismos como la separación de humanidad sobre naturaleza, sujeto sobre objeto, civilizado sobre bárbaro, mente sobre cuerpo, hombre sobre mujer. Estas categorías ideológicas clásicas sirven tanto para legitimar la devastación del mundo natural como para explotar las diferencias de sexo-género, raciales y culturales. Las feministas enfatizan el aspecto patriarcal de estos pares artificiales; los intelectuales del Sur global destacan su «colonialidad». De tal manera, el moderno sistema mundial colonial capitalista patriarcal (Grosfoguel y Mielants, 2006) margina y degrada las leyes, ciencias, economías y formas de conocimiento — como los cuidados - consideradas no

\footnotetext{
${ }^{3}$ Utilizado aquí en el sentido de una orientación «anti» o no espiritual y religiosa, no en el sentido de una orientación que respeta igualmente todos los sistemas de creencias, basados o no en la fe.

${ }^{4}$ 6. O, como argumenta Dobson (1995), «instrumentalismo humano», puesto que todos llegamos a ser, inevitablemente, un poco centrados en lo humano de manera neutral.
} 
occidentales. Tal es el modelo político dominante, aunque ha habido «otras» formas alternativas en Europa, así como «modernidades» en América Latina, China y otras regiones.

Este libro pretende abarcar una diversidad de visiones que incluyan desde el actual modelo globalizador de desarrollo hasta alternativas no modernas y autodefinidas. Muchas cosmovisiones radicales incluidas en este libro encajarían en la segunda o la tercera de estas categorías. Al dar voz a esta diversidad, compartimos la convicción de que la actual crisis no es coyuntural ni gestionable dentro de los marcos de referencia institucionales hoy vigentes. Es una crisis histórica y estructural, que requiere de una profunda toma de conciencia cultural y de la reorganización de las relaciones, tanto dentro como entre las sociedades de todo el mundo, y también entre los seres humanos y el resto de la así llamada «naturaleza». Como humanos, la lección más importante que debemos aprender es hacer las paces con el planeta y entre nosotros. En todas partes, la gente está experimentando maneras de satisfacer sus necesidades a la vez que reivindica los derechos y la dignidad de la Tierra y de sus precarios habitantes. Estas búsquedas son una respuesta al colapso ecológico, el acaparamiento de tierras, las guerras por el petróleo y prácticas de extractivismo como la agroindustria y las plantaciones de variedades genéticamente modificadas. En términos humanos, estas desposesiones traen consigo la pérdida de medios de supervivencia en el ámbito rural y el incremento de la pobreza urbana. A menudo, el «progreso» occidental da lugar o fomenta trastornos de opulencia, alienación y desarraigo. Pero en la actualidad pueden encontrarse movimientos populares de resistencia en todos los continentes. El Atlas de la justicia ambiental registra más de 2.000 conflictos $^{5}$, confirmando así la existencia de un movimiento mundial por la justicia ambiental, por más que no haya alcanzado todavía una voz única.

No existe ninguna garantía de que el desarrollo vaya a resolver la discriminación y la violencia tradicionales contra las mujeres, los jóvenes, los niños y las minorías intersexuales, como tampoco las que afectan a campesinos sin tierra, desempleados, razas, castas y grupos étnicos (Navas et al., 2018). A medida que el capital globalizado desestabiliza las economías regionales, convirtiendo a las comunidades en poblaciones de refugiados, algunos optan por

\footnotetext{
${ }^{5}$ El Atlas de la Justicia Ambiental reúne las experiencias de las comunidades que luchan por la justicia ambiental y es el mayor inventario mundial de conflictos ecológicos. Su propósito es visibilizar tales movilizaciones, evidenciar sus reivindicaciones y testimonios y abogar por una verdadera responsabilidad empresarial y estatal ante las injusticias provocadas por sus actividades (Martínez-Alier et al., 2016). Véase https://ejatlas.org/
} 
identificarse con el poder machista de la derecha política y su promesa de «recuperar los empleos» apropiados por los inmigrantes. A veces, también una izquierda de clase trabajadora puede llegar a adoptar esta postura. En todo el mundo se está dando una peligrosa deriva autoritaria, desde la India hasta Estados Unidos y Europa. La relativamente privilegiada clase tecnocrática puede promover una agenda neoliberal con sus quimeras de democracia representativa y una trayectoria innovadora en pos del crecimiento perpetuo. De todas formas, suele haber una línea difusa entre la derecha y la izquierda ortodoxas cuando se trata de la modernización y el progreso; además, ambas se fundamentan en valores eurocéntricos y masculinos.

Karl Marx nos recordaba que cuando una nueva sociedad surge desde dentro de la vieja, arrastra consigo muchos de los defectos del antiguo sistema. Posteriormente, Antonio Gramsci escribiría: «La crisis consiste precisamente en el hecho de que lo viejo está muriendo y lo nuevo no acaba de nacer; en este interregno surge una gran variedad de síntomas mórbidos» (Gramsci, 1971/1930: 275-276). Lo que estos intelectuales europeos no anticiparon es cómo hoy están surgiendo alternativas desde los márgenes políticos; tanto desde la periferia colonial como en la misma periferia interior del capitalismo. El análisis marxista continúa siendo necesario, pero no es suficiente. Requiere que se lo complemente con ideas -incluyendo al feminismo y otros imaginarios que surgen en el Sur global- como, por ejemplo, la perspectiva gandhiana. En una época de transición como la actual, la crítica y la acción requieren de nuevas narrativas, combinadas con soluciones materiales prácticas. Hacer más de lo mismo, aunque mejor, no es suficiente. El camino a seguir no se limita a lograr empresas multinacionales más transparentes o burocracias reguladoras fuertes; tampoco se ciñe a una cuestión de reconocimiento de la plena ciudadanía a las «personas de color», los «mayores», los «discapacitados», las «mujeres» o las «queer» según políticas liberales pluralistas. De igual modo, la conservación de unos pocos parches de naturaleza «prístinos» en los márgenes del capitalismo urbano de poco servirá para evitar el colapso de la biodiversidad.

Este diccionario aparece en un momento en que los dos grandes modelos del siglo XX - la democracia liberal representativa y el socialismo de Estado- se han vuelto formas de gobierno incoherentes y disfuncionales. Por consiguiente, comienza con algunas reflexiones sobre la idea de desarrollo, basándose en la experiencia de un/una académico/a-activista de cada continente, exceptuando la Antártida. Estas voces son las de Nnimmo Bassey (África), Van- 
dana Shiva (Asia), Kirk Huffman (Oceanía), José María Tortosa (Europa), Phil McMichael (América del Norte) y Maristella Svampa (América del Sur).

A continuación de estos análisis, el libro examina los límites del desarrollismo en su intento de hallar soluciones reformistas a las crisis globales. Veremos aquí al fantasma del desarrollo reencarnándose de infinitas maneras, mientras las miopes soluciones a la crisis propuestas por quienes detentan el poder intentan mantener el statu quo hoy vigente entre el Norte y el Sur. Esta sección contempla, entre otros temas, los mecanismos de mercado, la geoingeniería y la agricultura climáticamente inteligente, la cuestión demográfica, la economía verde, la ingeniería reproductiva y el transhumanismo. Aquí el tema primordial es el tan afamado gesto político del «desarrollo sostenible». Por supuesto, es probable que haya gente bienintencionada que (a veces inadvertidamente) proponga soluciones superficiales o falsas a los problemas globales. Pero, una vez más, no siempre resulta sencillo distinguir entre iniciativas convencionales o superficiales y aquellas «radicalmente transformadoras», especialmente cuando el complejo militar-industrial-mediático y el lavado de cara ecológico de la industria están en pleno apogeo seductor.

La crítica de la industrialización no es algo nuevo. Mary Wollstonecraft Shelley (1797-1851), Karl Marx (1818-1883) y Mohandas Gandhi (1869-1948), cada uno a su manera, expresaron sus reparos sobre ella, como lo han hecho también los movimientos populares durante los pasados dos siglos. En el último tercio del siglo XX el debate sobre la sostenibilidad estuvo fuertemente influenciado por el argumento que planteaba el informe al Club de Roma Los límites del crecimiento (Meadows et al., 1972), y a partir de la primera Conferencia de Naciones Unidas sobre Medio Ambiente y Desarrollo, realizada en Estocolmo en 1972, aun desde esferas oficiales se ha hecho pública la preocupación por las tecnologías de producción masiva y los patrones de consumo. Encuentros periódicos a nivel mundial volverían a destacar el desfase entre «desarrollo y medio ambiente», siendo el informe Nuestro futuro común (1987) el que más énfasis puso sobre tal asimetría. No obstante, ni los análisis de Naciones Unidas ni los gubernamentales han incluido nunca una crítica a las fuerzas sociales estructurales que favorecen la degradación ecológica. Los planteamientos siempre se han centrado en convertir al crecimiento económico y al desarrollo en «sostenibles e inclusivos» mediante tecnologías adecuadas, mecanismos de mercado y reformas políticas institucionales. El problema es que este mantra de la sostenibilidad fue rápidamente asimilado por el capitalismo, que luego lo vació de su contenido ecológico. 
A partir de la década de 1980 la globalización neoliberal se expandió agresivamente por todo el planeta. Fue entonces que Naciones Unidas desvió el foco hacia un programa de «mitigación de la pobreza» en los países en desarrollo, sin tampoco señalar como origen de dicha pobreza a una economía centrada en la acumulación, promovida por el Norte global acaudalado. Es más, se ha argumentado que los países deben alcanzar un elevado nivel de vida antes de poder destinar recursos para la protección del medio ambiente ${ }^{6}$. En tal sentido, el «crecimiento» económico fue reivindicado como un paso indispensable (Gómez-Baggethun y Naredo, 2015). Este debilitamiento de los debates iniciales sobre los límites permitió la entrada del ecológicamente moderno concepto de «economía verde». El nuevo milenio ha visto un sinfín de semejantes propuestas keynesianas: la bioeconomía, la Revolución Verde para África, la promoción de la economía circular tanto en China como en Europa, y la Agenda 2030 para el Desarrollo Sostenible (Salleh, 2016).

En la Conferencia de la ONU sobre Desarrollo Sostenible de 2012, esta hueca ideología de la sostenibilidad se convirtió en el marco de referencia para las discusiones multilaterales. Desde hace algún tiempo, el Programa de Naciones Unidas para el Medio Ambiente (PNUMA), junto con el sector empresarial, y hasta ciertos ámbitos de la izquierda política ${ }^{7}$, vienen hablando con entusiasmo de la necesidad de un «new deal verde». Como preparación de la cumbre Río+20, el PNUMA publicó un informe sobre la «economía verde», definiéndola como «la que tiene como resultado la mejora del bienestar humano y la equidad social, a la vez que reduce significativamente los riesgos ambientales y las carencias ecológicas» (Salleh, 2012; UNEP, 2011). En consonancia con las políticas favorables al crecimiento de los promotores del desarrollo sostenible, el informe conceptualiza a todas las formas naturales vivientes del planeta como «capital natural» $\mathrm{y}$ «activos económicos esenciales», intensificando de tal modo una mercantilización absoluta de la vida sobre la Tierra. No obstante, esta postura ha encontrado una feroz oposición por parte del sector altermundista.

La declaración final de Río+20 aboga por el crecimiento económico en más de veinte de sus artículos. Este enfoque se basa en una supuesta ecologización de la teoría económica neoclásica llamada «economía ambiental», es decir, la convicción en que el crecimiento se puede desvincular o desacoplar de la natu-

\footnotetext{
${ }^{6}$ Ver por ejemplo una presentación hecha por el ex primer ministro indio Manmohan Singh (1992), y una crítica a ella en Shrivastava y Kothari (2012: 121-122).

${ }^{7}$ Por ejemplo, la New Economics Foundation, Reino Unido y la oficina en Berlín de la Rosa Luxemburg Stiftung.
} 
raleza mediante la desmaterialización y la descontaminación a través de lo que se define como «ecoeficiencia». Análisis empíricos de los procesos «de la cuna a la tumba» y del metabolismo social demuestran que la producción se ha «desmaterializado» solo en términos relativos, utilizando menos energía y materiales por unidad de PIB; pero no ha reducido los volúmenes totales o absolutos de energía y materiales, que es lo que importa para la sostenibilidad. Históricamente, los únicos periodos de desmaterialización absoluta han coincidido con recesiones económicas ${ }^{8}$. La «eficiencia económica» no alcanza a respetar los límites biofísicos, tanto de la naturaleza y sus recursos, como de la capacidad de asimilación de los ecosistemas o los límites planetarios.

El modelo internacional de capitalismo verde propuesto en la declaración Transformar nuestro mundo: La Agenda 2030 para el desarrollo sostenible (Naciones Unidas, 2013, 2015; SDSN, 2013; UN Secretary General Panel, 2012; UNEP, 2011), revela las siguientes deficiencias (adaptado de Kothari, 2013):

- No analiza cómo las raíces estructurales de la pobreza, la insostenibilidad y la violencia multidimensional están históricamente asentadas en el poder estatal, los monopolios empresariales, el neocolonialismo y las instituciones patriarcales.

- Un énfasis insuficiente en la gobernanza democrática directa con la toma transparente de decisiones por parte de la ciudadanía y las comunidades autoconcientes, en contextos presenciales.

- El permanente énfasis en el crecimiento económico como impulsor del desarrollo, en contradicción con los límites biofísicos y con la arbitraria adopción del PIB como indicador de progreso.

- Dependencia permanente de la globalización económica como estrategia económica fundamental, lo que debilita los esfuerzos de los pueblos a favor de su autosuficiencia y autonomía.

- Sumisión permanente al capital privado y renuencia a democratizar el mercado mediante el control de los trabajadores-productores y de las comunidades.

- La ciencia y la tecnología modernas se presentan como panaceas sociales, que ignoran sus límites e impactos, y marginan «otros» conocimientos.

- Desprecio de la cultura, la ética y la espiritualidad, que son forzadas a someterse a los poderes económicos.

\footnotetext{
${ }^{8}$ Los economistas ecológicos han aportado numerosas evidencias empíricas con sus análisis sociometabólicos, que miden los flujos de energía y materiales dentro de la economía. Para ejemplos, consultar Krausmann et al. (2009) y Jorgenson y Clark (2012). Para una discusión sobre el método: Gerber y Scheidel (2018).
} 
- Consumismo desregulado sin estrategias para revertir la desproporcionada contaminación generada por el Norte global a través de sus desechos tóxicos y sus emisiones a la atmósfera.

- Cada vez más estructuras neoliberales de gobernanza global fundamentadas en valores de gestión tecnocrática por parte de burocracias estatales y multilaterales.

El esquema de las Metas para el Desarrollo Sostenible (MDS), con un alcance hoy global, se basa en un falso consenso ${ }^{9}$. Si el desarrollo es considerado un término tóxico que debe ser rechazado (Dearden, 2014), entonces el desarrollo sostenible se convierte en un oxímoron. Más específicamente, el teórico del decrecimiento Giorgos Kallis señala:

El desarrollo sostenible y su reencarnación más reciente, el «crecimiento verde», despolitizan a los genuinos antagonismos políticos entre las visiones alternativas para el futuro. Convierten a los problemas ecológicos en algo meramente técnico, prometiendo soluciones mutuamente beneficiosas y la meta imposible de perpetuar el crecimiento económico sin perjudicar al medio ambiente (Kallis, 2015).

No es nuestra intención infravalorar el trabajo de aquellos que investigan nuevas soluciones tecnológicas para reducir los problemas, como sería el caso de las energías renovables, ni tampoco menospreciar los muchos elementos positivos contenidos en el esquema de las Metas para el Desarrollo Sostenible ${ }^{10}$. Más bien, lo que pretendemos es destacar que si no se da una transformación sociocultural fundamental, la innovación tecnológica y en la gestión no nos ayudará a salir de las crisis ${ }^{11}$. A medida que los estados-nación y la sociedad civil se preparan para las MDS, resulta imperativo establecer criterios que ayuden a la gente a distinguir las opciones.

En contraposición al discurso de la razón política convencional, la sección principal de nuestro Diccionario reúne toda una gama de nociones y prácticas complementarias que prefiguran alternativas radicales y sistémicas (Para contribuciones anteriores: Beling et al., 2018; Escobar, 2015; Kothari et al., 2015; Salleh, 2017/1997). Algunas de estas recuperan o hacen una reinterpre-

\footnotetext{
${ }^{9}$ Este fenómeno fue anticipado en trabajos pioneros por Shiva (1989) y Hornborg (2009).

10 Para un análisis crítico pero apreciativo del potencial de las MDS, véase Club de Madrid (2017), A New Paradigm for Sustainable Development? Resumen (en inglés) de las deliberaciones del Grupo de Trabajo sobre Sostenibilidad Ambiental y Sociedades Inclusivas, http://www.clubmadrid.org/en/publicacion/a_new_paradigm_for_sustainable_development

11 Véase además http://www.lowtechmagazine.com/about.html
} 
tación creativa de arraigadas cosmovisiones indígenas, otras provienen de recientes movimientos sociales y otras reconsideran antiguas tradiciones filosóficas y religiosas. Todas ellas se preguntan ¿por qué nuestra vida cotidiana está tan mal actualmente?, ¿quién es el responsable?, ¿cómo sería una vida mejor? Y ¿cómo lograr su realización? Recordemos la pregunta planteada por las feministas a favor de la «sostenibilidad de la vida»: ¿Cómo es una vida que merece ser vivida y cuáles son las condiciones que permiten alcanzarla (Peréz Orozco, 2014)?

En conjunto, estas perspectivas configuran un «pluriverso»; un mundo en el que caben muchos mundos, como sostienen los zapatistas de Chiapas. Todos los mundos de la gente deberían coexistir con dignidad y en paz, sin sufrir menoscabo, explotación y miseria. Un mundo pluriversal supera el patriarcado, el racismo, las castas y otras formas de discriminación. En él, la gente reaprende qué significa ser una humilde parte de la naturaleza, y se supera las estrechas nociones antropocéntricas del progreso basado en el crecimiento económico. Pese a que muchas articulaciones pluriversales crean sinergias entre ellas, a diferencia de la ideología universalista del desarrollo sostenible, no pueden verse reducidas a una política global gestionada por unas Naciones Unidas u otro régimen mundial de gobernanza, como tampoco por regímenes regionales o estatales. Nosotros imaginamos una confluencia mundial de alternativas, generadora de estrategias para la transición y que incluya un sinfín de pequeñas acciones cotidianas que conduzcan a una gran transformación.

Nuestro proyecto de deconstrucción del desarrollo se abre en una matriz de alternativas. Algunas de ellas ya son bien conocidas en los círculos académicos y de activistas. Por ejemplo, el buen vivir, una «cultura de la vida» con diversos nombres en distintas regiones de América del Sur; ubuntu, que nos recuerda el valor sudafricano de la reciprocidad humana; swaraj, de la India, centrado en la autosuficiencia y el autogobierno (Gudynas, 2011; Kothari, 2014; Metz, 2011). El libro se basa en la hipótesis de que hay miles de tales modelos alrededor del mundo. Otros, menos conocidos pero igualmente relevantes, serían kyosei, minobimaatisiiwin, nayakrishi, así como las versiones críticamente reflexivas de las religiones mayores como el islam, el cristianismo, el budismo y el judaísmo. Del mismo modo, las visiones políticas como el ecosocialismo y la ecología profunda tienen puntos de convergencia con las antiguas ideas de comunalismo. Pese a que muchos términos tienen una larga historia, reaparecen en la narrativa de los movimientos por el vivir bien; y una vez más coexisten con conceptos contemporáneos como el decrecimiento y el ecofeminismo 
(Bennholdt-Thomsen y Mies, 1999; D'Alisa et al., 2014; Demaria et al., 2013; Salleh, 2017/1997).

Desde el norte, el sur, el este y el oeste, cada franja del arco iris posdesarrollista es un símbolo de la emancipación humana «dentro de la naturaleza» (Salleh, 2017/1997; Sousa Santos, 2009). Es el enlace esencial que distingue a nuestro proyecto pluriversal del relativismo cultural. Como dijera Aldo Leopold: «una cosa es adecuada cuando tiende a preservar la integridad, la estabilidad y la belleza de la comunidad biótica; es nociva cuando tiende a lo contrario» (Leopold, 1949: 224). En la tarea de hacer las paces con la Tierra, otra meta pacificadora es la vinculación de los conocimientos ancestrales con los contemporáneos, en un proceso que exige un diálogo horizontal y respetuoso. Más allá de esto, no hay planteamientos válidos para toda época y lugar, del mismo modo que no hay teoría que sea inmune al cuestionamiento. De hecho, este tipo de reflexibilidad histórica solo muy recientemente ha comenzado a ser reconocida como un ámbito de lo político. La respuesta a las estructuras de macropoder como el capital y el imperio es un escenario suficientemente transitado, pero lo que continúa siendo algo inexplorado es el campo del micropoder o poder capilar que alimenta las violencias cotidianas. Toda la respetable retórica de la justicia en abstracto, incluidas las loas espirituales a la Madre Tierra, no serán suficientes para alcanzar los cambios a los que aspiramos.

Es necesario plantear interrogantes fundamentales. ¿Cómo vamos desde aquí hasta allí, para concretar la transición hacia un pluriverso? Un Diccionario del posdesarrollo serviría para profundizar y ampliar un programa de investigación, diálogo y acción, tanto para el mundo académico, formuladores de políticas y activistas. Brindaría toda una serie de cosmovisiones y prácticas vinculadas a nuestra búsqueda colectiva de un mundo ecológicamente sabio y socialmente justo. Semejante agenda debería investigar el Qué, el Cómo, el Quién y el Porqué de todo aquello que es transformador, distinguiéndolo de lo que no lo es ${ }^{12}$. En la transición a un mundo posdesarrollista, tendremos acompañantes con una visión estratégica, así como otros con buenas propuestas tácticas a corto plazo. La democracia, como un proceso de permanente radicalización de sí mismo, debería incluir a todas las esferas de la vida, comenzando con el cuerpo y avanzando para afirmar su lugar en una plena Democracia de la Tierra ${ }^{13}$.

12 Para las ideas iniciales sobre la agenda del Diccionario del posdesarrollo, véase Demaria y Kothari (2017). A su vez, para un intento temprano de articular diferentes alternativas al desarrollo, véase Beling et al. (2018) que analiza sinergias discursivas entre Desarrollo Humano, Decrecimiento y Buen Vivir para una «gran transformación» en pos de la sostenibilidad.

${ }^{13}$ Shiva: http://www.navdanya.org/earth-democracy 
Las alternativas transformadoras se diferencian en muchos aspectos de las soluciones ortodoxas o reformistas. Idealmente, deberían ir a la raíz de los problemas. En segunda instancia, tendrían que cuestionar todo aquello que ya hemos identificado como los rasgos esenciales del discurso desarrollista, como el crecimiento económico, la retórica del progreso, la racionalidad instrumental, los mercados, la universalidad, el antropocentrismo, el sexismo, etcétera. En tercer lugar, tendrían que basarse en una ética radicalmente diferente a la que sustenta al sistema actual. Las entradas en esta sección del libro reflejan valores fundamentados en una lógica relacional. Un mundo en el que todo está conectado con todo lo demás; es decir, sociedades que incluyan los siguientes valores, entre otros más:

— diversidad y pluriversidad

- autonomía y autosuficiencia

- solidaridad y reciprocidad

- procomún y ética colectiva

- comunión con - y derechos de - la naturaleza

— interdependencia

- simplicidad y sentido de la suficiencia

— inclusividad y dignidad

— justicia y equidad

— rechazo de las jerarquías

- dignidad del trabajo

— derechos y responsabilidades

— sostenibilidad ecológica

- no violencia y paz ${ }^{14}$

Cuarto, la acción política corresponderá a los marginados, explotados y oprimidos. Y quinto, la transformación requerirá integrar y movilizar a múltiples dimensiones: políticas, económicas, sociales, culturales, éticas, materiales o espirituales, aunque no necesariamente todas a la vez. Hay diversos senderos hacia una biocivilización.

Un ejemplo de tal visión podría ser el conjunto de confluencias llamado Vikalp Sangam que se viene desarrollando en India desde $2014^{15}$. Los valores promovidos por este movimiento son:

\footnotetext{
${ }^{14}$ Para un proceso extensivo e intensivo de visualización de los elementos y valores de las alternativas radicales, véase el proceso Vikalp Sangam (Confluencias Alternativas) en la India, iniciado en 2014: http://www.kalpavriksh.org/index.php/ alternatives/alternatives-knowledge-center/353-vikalp-sangamcoverage; y la visión que de él surge, en http://www.vikalpsangam.org/about/the-search-for-alternatives-key-aspects-and-principles/

15 Adaptado de la nota sobre la visión del Vikalp Sangam, en http://www. vikalpsangam.org/about/the-search-for-alternatives-key-aspects-and-principles/
} 
- Sabiduría ecológica, integridad y resiliencia: donde se prioriza la conservación de los procesos ecorregeneradores que sostienen a los ecosistemas, las especies, las funciones y los ciclos, respetando los límites ecológicos desde lo local hasta lo global y donde se incorpora la ética ecológica en todas las actividades humanas.

- Bienestar social y justicia: donde su realización incluye lo físico, lo social, lo cultural y lo espiritual; hay equidad en lo concerniente a derechos y responsabilidades socioeconómicas y políticas. Las relaciones no discriminatorias y la armonía comunitaria reemplazan a las jerarquías basadas en la fe, el género, la casta, la clase, el origen étnico, las capacidades o la edad, y se garantizan los derechos humanos colectivos e individuales.

- Democracia directa y delegación: donde la toma de decisiones por consenso se practica en los asentamientos humanos pequeños, en los que todas las personas tienen el derecho, la capacidad y la oportunidad de participar, fortaleciendo la gobernanza democrática a través de delegados responsables de rendir cuentas, y de manera consensual, respetuosa y solidaria con las necesidades y los derechos de quienes se encuentran marginados, por ejemplo, los jóvenes y las minorías religiosas.

- Democratización económica: donde la propiedad privada cede el paso al procomún, eliminando las distinciones entre propietario y trabajador; y donde las comunidades y los individuos —idealmente «prosumidores»- disfrutan de autonomía en los ámbitos de la producción, la distribución y los mercados locales, donde la localización es un factor esencial y el comercio se basa en el principio de intercambio equitativo.

- Diversidad cultural y democracia del conocimiento: donde se respeta la pluralidad de estilos de vida, ideas e ideologías, se fomentan la creatividad y la innovación y todo el mundo tiene acceso a la generación, transmisión y uso del conocimiento, ya sea tradicional o moderno, incluyendo a la ciencia y la tecnología.

Pero ¿dónde están las mujeres — «la otra mitad» de la humanidad - en todo esto? ¿Cómo garantizar que un pluriverso posdesarrollista no acabe con la «colonialidad» pero mantenga a las mujeres «en su sitio» como las encargadas materiales de las actividades cotidianas vitales? Un primer paso para anticipar el profundo cambio sistémico necesario es plantearnos cómo las prácticas y conocimientos, tanto tradicionales como modernos, privilegian los valores y las 
oportunidades masculinas. Originalmente, las palabras «economía» y «ecología» surgen de la raíz común griega oikos, que significa «hogar». Pero pronto este origen común fue perdiendo visibilidad a medida que el autoproclamado dominio masculino de la naturaleza fomentaba la explotación de las energías femeninas. Civilizaciones enteras se han asentado sobre el control sexual y de género de la fertilidad femenina; el recurso esencial para la continuidad de cualquier régimen político. Tal cosa convirtió a las mujeres en «medios» en lugar de «fines», arrebatándoles su condición de seres humanos integrales.

Irónicamente, la economía, o como se le llama en el Norte global, el sector productivo, actualmente está destruyendo sus propias bases sociales y ecológicas en el sector reproductivo. El libro contiene diversas entradas sobre los cuestionamientos de las mujeres a esta irracional ética desarrollista: feminismo latinoamericano y del Pacífico, PeaceWomen, matriarcados, salarios para el trabajo doméstico, política del cuerpo, economías del don y ecofeminismo. La mayoría de tales iniciativas se fundamentan en las luchas de las mujeres por la supervivencia. Vinculan la emancipación política con la justicia ambiental, los problemas locales con las estructuras globales, a menudo defendiendo la subsistencia sostenible frente al progreso lineal y el «ponerse al día con el desarrollo».35 En cambio, el feminismo occidental ortodoxo tiende a ser antropocéntrico, por lo que las feministas liberales y aun las socialistas pueden ser apaciguadas con el mantra de la «igualdad». De tal modo, sus políticas pueden acabar siendo, aunque involuntariamente, un mero parche a las actuales instituciones con sesgo masculino.

Así como los análisis oficiales de Naciones Unidas y gubernamentales nunca han incluido una crítica a las fuerzas estructurales que están detrás de la debacle ecológica, también se echa de menos un análisis de la estructura de las antiguas actitudes patriarcales que el desarrollismo global continúa manteniendo. Conocida como «la última revolución», la liberación de las mujeres de la dominación de los hombres no será tarea sencilla. Con demasiada frecuencia, los expertos en política vinculan el bienestar familiar o comunitario con el bienestar del cabeza de familia, ignorando la jerarquía de poder en el ámbito doméstico. Un sector académico posmoderno que reduce la identidad sexual al constructo de «género» no es de gran ayuda; del mismo modo, tratar «la raza, la clase y el género» como «estructuras intersectoriales» abstractas puede desviar la atención de la enorme relevancia de las experiencias vividas. Gestos democráticos formales como el voto o la igualdad salarial para las mujeres pueden 
acabar encubriendo la opresión de sexo y género ${ }^{16}$. En una línea similar, una adhesión a las virtudes espirituales o a sólidos principios seculares como la diversidad o la solidaridad pueden ayudar, pero no garantizan el fin de los impactos biofísicos de la violencia sexual y de género.

Los activistas que buscan alternativas justas y sostenibles tienen que reconocer este nivel tácito de relevancia política. En diversos grados, las mujeres del Norte y del Sur viven silenciadas y hostigadas, y carecen tanto de recursos como de libertad de movimiento. Viven con indignidades culturalmente establecidas acerca de la menstruación, la ablación del clítoris, la poligamia, los asesinatos relacionados con la dote, los homicidios por honor, el «suttee» (en la India, suicidio ritual de una viuda), los pellizcos, el manoseo y, más recientemente, el porno digitalizado de venganza. Soportan embarazos obligados, palizas domésticas, violaciones maritales, violaciones de bandas juveniles o violaciones genocidas utilizadas como arma de guerra, la estigmatización como viudas y la persecución por «brujas» cuando son ancianas. En el siglo XXI, una combinación de feticidio, violencia privada y daños militares colaterales entre la población civil está teniendo como resultado — a escala mundial — un descenso de la tasa demográfica femenina en relación con la masculina. Solo en Asia, durante la última década, un millón y medio de mujeres han perdido la vida debido a tales factores.

El abuso infantil y la crueldad con los animales son otros aspectos de la arcaica pero aún extendida prerrogativa patriarcal sobre formas de vida «inferiores». Estas actividades son una forma de extractivismo; una gratificación obtenida de energías extraídas de otros cuerpos considerados «más próximos a la naturaleza». Las mujeres académicas han ofrecido un análisis histórico y una crítica trascendente del orden patriarcal del capitalismo global, su economía y su ciencia, deconstruyendo los dualismos divisorios de humanidad sobre naturaleza, hombre sobre mujer, jefe sobre trabajador, blanco sobre negro. Una cada vez más visible «política de los cuidados» postulada por las mujeres del Norte y el Sur globales converge con las tradiciones del buen vivir, ubuntu y swaraj, porque en ambos hemisferios las funciones cotidianas de las mujeres enseñan «otra lógica», no controladora ni instrumental, sino «relacional»; como la racionalidad de los procesos ecológicos (Salleh, 1997/2017, 2011, 2012). En su articula-

\footnotetext{
${ }^{16}$ Los salarios de las mujeres en las economías desarrolladas equivalen al $65 \%$ de los salarios masculinos por trabajos equivalentes. En estas economías, los hombres pasan menos de 20 minutos diarios con sus hijos. En la India moderna, solo el 15\% de las mujeres forma parte de la fuerza de trabajo remunerada.
} 
ción más profunda, estas voces pluriversales cuestionan tanto a la modernidad como al tradicionalismo al colocar la personificación material de clase, raza, sexo-género y especie dentro de un marco ecocéntrico. No puede haber pluriverso hasta que los fundamentos históricos del privilegio masculino no pasen a formar parte del debate político.

Los lectores podrán legítimamente cuestionar la confianza que nosotros y numerosos colaboradores en el Diccionario depositamos en la idea de «comunidad». Sin lugar a duda, es un término cuestionable, que fácilmente puede ocultar opresiones basadas en el sexo-género, la edad, la clase, la casta, el origen étnico, la raza o las capacidades. También debemos reconocer que la gobernanza o la economía «localizadas» son a menudo xenófobas; un provincianismo o campanilismo que actualmente vemos en la oposición nacionalista a los refugiados en muchos lugares del mundo. Asediado por la intolerancia desde la derecha y por una defensiva «política de la identidad» desde la izquierda, nuestro compendio de alternativas propone prácticas integradoras e inclusivas. Los elementos afirmadores de la vida pueden encontrase hasta en algunas de las religiones patriarcales del mundo y esperamos fomentar este potencial.

El ideal de comunalidad aquí vislumbrado bebe del paradigmático espíritu compartido por muchos movimientos actuales a favor de «la puesta en común». Como en el caso de las iniciativas promovidas por el Vikalp Sangam, estos colectivos se basan en la toma autónoma de decisiones en relaciones cara a cara, y en el intercambio económico enfocado a satisfacer las necesidades básicas mediante la autosuficiencia ${ }^{17}$. Nuestra interpretación de la comunidad es de carácter crítico; siempre «en proceso» y cuestionando la moderna hegemonía capitalista patriarcal de «el individuo» como núcleo de la sociedad. Esperamos que este libro impulse a los movimientos opuestos a la presión colonizadora global, inspirados, como lo estamos nosotros, por grupos culturales de todo el mundo que aún disfrutan de una existencia colectiva ${ }^{18}$. En tal contexto, la socióloga mexicana Raquel Gutiérrez Aguilar propone el concepto de entramados comunitarios:

\footnotetext{
${ }^{17}$ Para un relato detallado sobre la legitimidad de usar «comunidad» y sus diversos derivados, reconociendo las refutaciones, véase Escobar $(2010,2014)$.

${ }^{18}$ Ver http://www.congresocomunalidad2015.org/ para detalles sobre el Primer Congreso Internacional sobre Comunalidad, realizado en Puebla, México en 2015, donde estos temas se discutieron extensamente.
} 
[...] la multiplicidad de mundos humanos que pueblan y engendran al mundo según diversas normas de respeto, colaboración, dignidad, amor y reciprocidad, que no están completamente subordinados a la lógica de la acumulación capitalista, aunque con frecuencia sufran sus ataques o estén abrumados por ella [...] estos entramados comunitarios [...] se encuentran en diversos formatos y concepciones [...] Incluyen las diversas e inmensamente variadas configuraciones colectivas humanas, algunas de ellas antiguas, otras más recientes, que otorgan sentido y aportan lo que en la filosofía política clásica se conoce como «espacio socionatural». (Gutiérrez Aguilar, 2013: 33)

Muchas cosmovisiones y prácticas radicales incluidas en este libro permiten visibilizar el pluriverso. Al presentarlas aquí, afirmamos su existencia y viabilidad. Es más, la propia proliferación de reivindicaciones provenientes de estos «otros» mundos es lo que hace posible a este libro. Inversamente, es en este sentido que las soluciones desarrollistas ortodoxas o reformistas pueden considerarse falsas. Como respuesta a la crisis ecológica, los «expertos» del Norte global se basan en el concepto de «Un Mundo» responsable de la devastación del planeta como el punto de partida de sus supuestas soluciones. No obstante, su compromiso con la dolce vita no puede ayudarnos en la fundamental tarea de lograr que el pluriverso sea sostenible. Repitámoslo: la noción de pluriverso pone en cuestión el mismísimo concepto de universalidad, tan central a la modernidad eurocéntrica. «Un mundo donde quepan muchos mundos»; los zapatistas nos ofrecen la más precisa y adecuada definición del pluriverso.

Aunque Occidente consiguió vender su propia idea de «Un Mundo», conocido solo por la ciencia moderna y regido por su propia cosmovisión, los movimientos alterglobalización proponen en cambio la pluriversidad como un proyecto basado en la multiplicidad de «formas de hacer mundo». Debido a las asimetrías de poder, los pueblos indígenas han tenido que enajenar su propia experiencia del mundo, asentada en el sentido común, y aprender a vivir con el dualismo masculinista eurocéntrico entre humanos y no humanos, que lleva a tratar a estos últimos como «recursos naturales». No obstante, suelen rechazar y resistirse a esta separación cuando se movilizan en defensa de montañas, lagos o ríos por considerarlos seres sentientes con «derechos» y no solo objetos o recursos. Por otro lado, muchas personas reflexivas del mundo industrializado están reivindicando que los derechos para el resto de la naturaleza se concreten en leyes y políticas. Al hacer tal cosa, se están aproximando a aquello que los pueblos indígenas siempre han integrado en sus cosmovisiones, solo que lo reclaman mediante las vías formales a las que están acostumbradas ${ }^{19}$. Queda mucho camino por recorrer para que la multiplicidad de mundos se convierta en algo

\footnotetext{
${ }^{19}$ Véase por ejemplo, Kauffman y Sheehan (2018); y https://therightsofnature.org.
} 
plenamente complementario, pero los movimientos por la justicia y por la ecología encuentran — cada vez más - puntos de coincidencia; y otro tanto sucede con las luchas políticas de las mujeres.

Tanto en el Norte como en el Sur globales, cada vez con mayor frecuencia se ve a madres y abuelas que brindan cuidados uniéndose a esta tendencia, defendiendo y recuperando maneras comunales de vivir y formas de autonomía basadas en el lugar. Al hacer tal cosa, al igual que los indígenas citados más arriba, ellas se inspiran en modos no patriarcales de hacer, sentir y conocer ${ }^{20}$. Fomentan la participación, la colaboración, el respeto y la aceptación mutua, de forma horizontal y valorando la sacralidad del ciclo de renovación de la vida. Sus culturas tácitamente matriarcales rechazan las ontologías basadas en la dominación, la jerarquía, el control, el poder, la negación del otro, la violencia y la guerra. Desde el movimiento mundial PeaceWomen hasta las redes antiextractivistas de África, las mujeres están defendiendo a la naturaleza y a la humanidad con el lema: «no hay descolonización sin despatriarcalización».

Todas estas iniciativas encuentran eco en los conceptos posdesarrollistas aquí descritos (Acosta y Brand, 2017). Porque el pluriverso no es simplemente un concepto que aspira a estar de moda, sino una práctica. Los imaginarios sociales basados en los derechos humanos y en los derechos de la naturaleza no se alcanzarán mediante intervenciones de arriba hacia abajo. Iniciativas tales como el Movimiento por la Transición o las Ecoaldeas pueden contener una mezcla de soluciones reformistas y cambios sistémicos más amplios. Los proyectos emancipatorios deberán basarse en la solidaridad intercontinental, pudiendo trabajar codo a codo con movimientos de resistencia como la iniciativa Yasuní-ITT de Ecuador y otras similares, exigiendo «dejar el petróleo en el subsuelo, el carbón en la mina y las arenas bituminosas en el terreno» (Acosta, 2014). Vivir según las visiones de múltiples mundos parcialmente conectados, aunque radicalmente diferentes, puede ayudarnos a controlar los universos y certidumbres tradicionales y modernas en nuestras vidas personales y colectivas. Como editores de $U n$ diccionario del posdesarrollo, aspiramos a proporcionar ciertos conceptosherramienta y prácticas que nos permitan tejer el pluriverso entre todos, fomentando una biocivilización que sea ecocéntrica, diversa y multidimensional; capaz de encontrar un equilibrio entre las necesidades individuales y las comunales. Esta política prefigurativa viva se fundamenta en el principio de crear ahora

20 42. Esta ética no debería ser leída a través de las gafas de la ideología liberal; es decir, como la «naturaleza esencial» de las mujeres. Se trata de una consecuencia de las experiencias de tareas de cuidado, históricamente asignadas a las mujeres en la mayoría de las culturas. 
los mundos que queremos que cristalicen en el futuro; esto implica una coherencia entre medios y fines.

Pero ¿cómo llegamos desde aquí hasta allí? Después de todo, estamos hablando de profundas transformaciones en los ámbitos de la economía, la política, lo social, lo cultural y una sexualidad viva. Semejante transición implica aceptar un conjunto de medidas y cambios en diversas esferas de la vida y a diferentes escalas geográficas. Las transiciones pueden ser complicadas y no suficientemente radicales, pero puede considerárselas «alternativas» si al menos aportan un potencial para el cambio. Teniendo en cuenta la diversidad de visiones imaginativas en todo el planeta, queda abierto el interrogante de cómo tejer sinergias entre ellas. Sin duda habrá contratiempos y estrategias que se desvanecerán para dar lugar a otras. Existirán las diferencias, las tensiones y hasta las contradicciones, pero todas ellas pueden servir de fundamento para el cambio constructivo. Las vías al pluriverso son múltiples, abiertas y están en constante evolución.

\section{REFERENCIAS}

Acosta, A. (2014). Iniciativa Yasuni-ITT: La difícil construcción de la utopía. Disponible en http://www.rebelion.org/noticia.php?id=180285

Acosta, A., y Brand, U. (2017). Salidas del laberinto capitalista. decrecimiento y postextractivismo. Barcelona, España: Icaria.

Beling, A., Vanhulst, J., Demaria, F., Rabid, V., Carballo, A., y Pelenc, J. (2018). Discursive synergies for a 'Great Transformation' towards sustainability: pragmatic contributions to a necessary dialogue between Human Development, Degrowth, and Buen Vivir. Ecological Economics, (144), pp. 304-313. https://doi.org/10.1016/j.ecolecon.2017.08.025

Bennholdt-Thomsen, V., y Mies, M. (1999). The Subsistence Perspective. Londres, Reino Unido: Zed Books.

D’Alisa, G., Demaria, F., y Kallis, G. (2014). Degrowth: a Vocabulary for a New Era. Londres, Reino Unido: Routlege. https://doi.org/10.4324/9780203796146

Dearden, N. (2014). Is development becoming a toxic term? The Guardian, 22 de enero de 2014. Disponible en http://www.theguardian.com/global-development-professionalsnetwork/2015/jan/22/development-toxic-term?CM-P=share_btn_tw

Deb, D. (2009). Beyond Developmentality. Nueva Delhi, India: Daanish Books.

Demaria, F., y Kothari, A. (2017). The Post-Development Dictionary Agenda: paths to the pluriverse. Third World Quarterly, (38), pp. 2588-2599. https://doi.org/10.1080/01436597.2017.1350821

Demaria, F., Schneider, F., Sekulova, F., y Martínez-Alier, J. (2013). What is degrowth? From an activist slogan to a social movement. Environmental Values, (22), pp. 191-215. https://doi.org/10.3197/096327113X13581561725194

Dobson, A. (1995). Green Political Thought. Londres, Reino Unido: Routledge. 
Escobar, A. (1995). Encountering Development. Princeton, NJ: Princeton University Press.

Escobar, A. (2010). Latin America at a Crossroads: Alternative Modernizations, Post-liberalism, or Postdevelopment? Cultural Studies 24(1), pp. 1-65. https://doi.org/10.1080/09502380903424208

Escobar, A. (2014). Sentipensar con la tierra: Nuevas lecturas sobre sobre desarrollo, territorio y diferencia. Medellín, Colombia: UNAULA.

Escobar, A. (2015). Degrowth, post-development, and transitions: a preliminary conversation. Sustainability Science, 10(3), pp. 451-462. https://doi.org/10.1007/s11625-015-0297-5

Gutiérrez Aguilar, R. (2013). Pistas reflexivas para orientarnos en una turbulenta época de peligro. En R. Gutiérrez et al. (eds.), Palabras para tejernos, resistir y transformar en la época que estamos viviendo (pp. 9-34). Oaxaca, México: Pez en el Árbol.

Gerber, J.-F., y Arnim, S. (2018). In Search of Substantive Economics: Comparing Today»s Two Major Socio-Metabolic Approaches to the Economy - MEFA and MuSIASEM. Ecological Economics, (144), pp. 186-194. https://doi.org/10.1016/j.ecolecon.2017.08.012

Gómez-Baggethun, E., y Naredo, J. M. (2015). In search of lost time: the rise and fall of limits to growth in international sustainability policy». Sustainability Science, 10(3), pp. 385-395. https://doi.org/10.1007/s11625-015-0308-6

Gramsci, A. (1971/1930). Selections from the Prison Notebooks. Nueva York, NY: International Publishers.

Grosfoguel, R., y Mielants, E. (2006). The Long-Durée Entanglement between Islamophobia and Racism in the Modern/Colonial Capitalist/Patriarchal World-System: An Introduction. Human Architecture: Journal of the Sociology of Self-Knowledge, 5(1). Disponible en https://scholarworks.umb.edu/humanarchitecture/vol5/iss1/2/

Gudynas, E. (2011). Buen vivir: today's tomorrow. Development, 54(4), pp. 441-447. https://doi.org/10.1057/dev.2011.86

Hornborg, A. (2009). Zero-Sum World. International Journal of Comparative Sociology, 50(3-4), pp. 237-262. https://doi.org/10.1177/0020715209105141

Jorgenson, A., y Clark, B. (2012). Are the Economy and the Environment Decoupling? A Comparative International Study: 1960-2005. American Journal of Sociology, 118(1), pp. 1-44. https://doi.org/10.1086/665990

Kallis, G. (2015). The Degrowth Alternative. Great Transition Initiative. Disponible en http://www.greattransition.org/publication/the-degrowth-alternative

Kauffman, C., y Sheehan, L. (2018). The Rights of Nature: Guiding our responsibilities through standards. En S. Turner, D. Shelton, J. Razaqque, O. Mcintyre, y J. May (eds.), Environmental Rights: The Development of Standards (pp. 342-365). Cambridge, Reino Unido: Cambridge University Press. https://doi.org/10.1017/9781108612500.016

Kothari, A. (2013). Missed Opportunity? Comments on two global reports for the post-2015 goals process. Pune, Kalpavriksh and ICCA Consortium. Disponible en http://www.unngls.org/IMG/pdf/Kalpavriksh_and_icca_Consortium_-_Post-2015_reports_critique__Ashish_Kothari_July_2013.pdf

Kothari, A. (2014). Radical ecological democracy: A way for India and beyond. Development, 57(1), pp. 36-45. https://doi.org/10.1057/dev.2014.43 
Kothari, A., Demaria, F., y Acosta, A. (2015). Buen vivir, degrowth and ecological swaraj: alternatives to development and the green economy. Development, 57(3), pp. 362-375. https://doi.org/10.1057/dev.2015.24

Krausmann, F., Gingrich, S., Eisenmenger, N., Erb, K.-H., Haberl, H., y Fischer-Kowalski, M. (2009). Growth in global materials use, GDP and population during the 20th century. Ecological Economics, 68(10), 2696-2705. https://doi.org/10.1016/j.ecolecon.2009.05.007

Leopold, A. (1949). A Sand County Almanac and Sketches Here and There. Nueva York, NY: Oxford University Press.

Martínez-Alier, J., Temper, L., Del Bene, D., y Scheidel, A. (2016). Is There a Global Environmental Justice Movement? Journal Peasant Studies, (43), pp. 731-755. https://doi.org/10.1080/03066150.2016.1141198

Meadows, D., Meadows, D., Randers, J., y Behrens, W. (1972). The Limits to Growth. Nueva York, NY: Universe Books.

Metz, T. (2011). Ubuntu as a moral theory and human rights in South Africa. African Human Rights Law Journal, 11(2), pp. 532-559.

Mies, M. (1986). Patriarchy and Accumulation on a World Scale. Londres, Reino Unido: Zed Books.

Naciones Unidas. (2013), A New Global Partnership: Eradicate Poverty and Transform Economies Through Sustainable Development, The Report of the High-Level Panel of Eminent Persons on the Post-2015 Development Agenda. Nueva York, NY: Naciones Unidas.

Naciones Unidas. (2015). Transforming our World: The 2030 Agenda for Sustainable Development. Nueva York, NY: Naciones Unidas.

Nandy, A. (2003). The Romance of the State and the Fate of Dissent in the Tropics. Nueva Delhi, India: Oxford University Press.

Navas, G., Mingorria, S., y Aguilar, B. (2018). Violence and resistance: An analysis of 95 environmental conflicts in Central America. Sustainability Science, «The EJAtlas: Ecological Distribution Conflicts as Forces for Sustainability». Disponible en https://link.springer.com/journal/11625/topicalCollection/AC_b4bf79ebe46fa50dcd805 39725659023

PNUMA (Programa de Naciones Unidas para el Medio Ambiente). (2011). Towards a Green Economy: Pathways to Sustainable Development and Poverty Eradication A Synthesis for Policy Makers. Nairobi, Kenia: Programa de Naciones Unidas para el Medio Ambiente.

Salleh, A. (2006), We in the North are the Biggest Problem for the South: A Conversation with Hilkka Pietila. Capitalism Nature Socialism, 17(1), pp. 44-61. https://doi.org/10.1080/10455750600704505

Salleh, A. (2011), Climate Strategy: Making the Choice between Ecological Modernisation or 'Living Well'. Journal of Australian Political Economy, (66), pp. 124-149.

Salleh, A. (2012), Green Economy or Green Utopia? Rio+20 and the Reproductive Labor Class. Journal of World Systems Research, 18(2), pp. 141-145. https://doi.org/10.5195/jwsr.2012.468 
Salleh, A. (2016), Climate, Water, and Livelihood Skills: A post-development reading of the $\begin{array}{llll}\text { SDGs. } & \text { Globalizations, } & \text { 952-959. }\end{array}$ https://doi.org/10.1080/14747731.2016.1173375

Salleh, A. (2017/1997). Ecofeminism as Politics: nature, Marx, and the postmodern. Londres, Reino Unido: Zed Books.

SDSN (Sustainable Development Solutions Network). (2013). An Action Agenda for Sustainable Development: Report for the UN Secretary General, Sustainable Development Solutions Network. Disponible en http://unsdsn. org/wp-content/uploads/2013/06/140505-AnAction-Agenda-for-Sustainable-Development.pdf

Shiva, V. (1989). Staying Alive: Women, Ecology and Development. Londres, Reino Unido: Zed Books.

Shrivastava, A., y Kothari, A. (2012). Churning the Earth: The Making of Global India. Nueva Delhi, India: Viking/Penguin.

Singh, M. (1992). Environment and the new economic policies. Foundation Day Lecture, Society for Promotion of Wastelands Development, Nueva Delhi, 17 de junio.

Sousa Santos, B. de (2009), A Non-Occidentalist West? Learned Ignorance and Ecology of Knowledge. Theory, Culture and Society, 26(7-8), pp. 103-125. https://doi.org/10.1177/0263276409348079 